\section{Sitting on the fence}

\author{
Stephen B Hanauer
}

I can see both sides of an issue that was recently discussed in the New England Journal of Medicine-"Executive Physicals-Bad Medicine on Three Counts" (Rank B [2008] N Engl J Med 359: 1424-1425). Brian Rank, Medical Director of the Health Partners Medical Group and Clinics in Minneapolis, MN, USA, disdained the 'executive physical' as failing to demonstrate efficacy, cost-effectiveness, and fairness (these expensive medical examinations are only offered to executives; they involve comprehensive tests and evaluations, the results of which are usually made available on the same day). Rank argued that no data support the concept that "...the most health care is the best health care"; by contrast, substantial evidence suggests that "...unnecessary testing may cause more harm than good." He propones that tests should be performed only when clinically indicated and notes that executive physicals reinforce the misperception that an expensive examination is better than a low-cost one. He describes this notion as "an indefensible idea that should not be promoted by the health care industry." Finally, he debates the issue of disparities in access to health care. Efforts to counter such disparities are undermined by the perpetuation of executive physicals, which "maintain the health of [a company's] wealthy senior executives while relegating the masses to something less."

I asked the Director of the Executive Health Program at my institution to respond to Rank's comments. The Director responded that the value of a thorough medical examination for a highly-compensated executive who would not otherwise routinely receive one cannot be understated; many executives do not participate in preventive medicine programs, so the executive physical "forces their hand". ...the net result is that healthcare systems in the US are struggling to meet the "bottom line"

SB Hanauer is Editorin-Chief of Nature Clinical Practice Gastroenterology \& Hepatology.

\section{Competing interests}

The author declared no competing interests.

www.nature.com/clinicalpractice doi:10.1038/ncpgasthep1302
Furthermore, the Director argued that executive physicals do not inherently generate the attitude that 'more is better', and said that the services provided (at least in our center) were not extravagant or excessive. He suggested that although the cost of executive physicals might seem high-mostly because coordinating a comprehensive examination in one day incurs cost penalties - the cost to the company would be much higher in terms of lost productivity if highly compensated employees had to be absent for multiple days for the purpose of undertaking tests. Finally, our Director agreed that although it is true that executive health programs give a sense of exclusivity, if someone is willing to pay a premium for essentially the same services as are provided in a regular examination, why would one not allow or enable that? As company health-care systems are expensive to run and often struggle to make ends meet, if individuals are willing to pay extra for the luxury of a fluffy towel and slippers, why not take their money and increase the financial stability of your total enterprise so that you can continue to provide much-needed services in other areas?

The net result is that health-care systems in the US are struggling to meet the 'bottom line'. At my institution, executive physicals are valued because although these highly profitable examinations do increase the overall costs of the health-care system, they enable our medical center to subsidize the costs of the considerable amount of care we provide to underserved and/or underinsured individuals. I don't know whether a similar rationale underlies the practices of other institutions that offer executive physicals...it's a matter for their own conscience. 